\title{
Hubungan Antara Pengetahuan dan Paritas Ibu dengan Perawatan Luka Perineum di Bidan Praktik Mandiri Ratna Wilis Palembang Tahun 2018
}

\author{
Risa Devita ${ }^{1}$, Aspera $^{2}$ \\ ${ }^{1,2}$ Lecture of STIKES 'Aisyiyah Palembang \\ Corresponding author: Risa Devita \\ Email:risa_devita@yahoo.com
}

Received: March13 ${ }^{\text {th }}, 2019$; Revised: April 11 $1^{\text {th }}, 2019$; Accepted: April 24 $4^{\text {th }}, 2019$

\begin{abstract}
Perineal care procedure by postpartum mothers is very important in preventing infection. Perineal care procedure can be done by applying ice pack compress, applying topical medications such as antiseptic fluid and performing kegel's exercise. Perineal wound care procedure can be conducted when bathing, after urination and after defacation. The purpose of this research was to find out the correlation between mothers' knowledge and parity and perineal care procedure in Independent Midwifery Practice (BPM) Ratna Wilis Palembang in 2018.Design research used surveyanalitik method with cross sectionalapproach, the samples of this research were taken by using accidental sampling method as many as 32 postpartum mothers who were hospitalized or mothes who came for a visit during their puerperium period to Independen Midwifery Practice (BPM) Ratna Wilis Palembang in 2018. The research was conducted from November 2018 - January 2019. The data were analyzed by using chi-square test with significance level $95 \%$ and $\alpha(0,05)$.The results of chi-square test showed the value of mothers' knowledge variable with $(\rho$ value $=0,000)$ and the value of mothers' parity variable with ( $\rho$ value $=$ 0,003 ) which indicated that statistically was a correlation between mothers' knowledge and parity with perineal care procedure in Independent Midwifery Practice (BPM) Ratna Wilis Palembang in 2018.Recommendedthat the health personnel in Independent Midwifery Parctice Ratna Wilis Palembang socialize about the perineal care procedure to increase mothers' knowledge of importance of perineal care procedure.
\end{abstract}

Keyword: Knowledge; parity; perineal care procedure

\section{Pendahuluan}

Masa nifas (puerperium) merupakan masa yang dimulai setelah kelahiran plasenta dan berakhir ketika alat-alat kandungan kembali seperti keadaan sebelum hamil (Maryunani, 2011). Pelayanan pasca persalinan harus terselenggara pada masa itu untuk memenuhi kebutuhan ibu dan bayi, yang meliputi upaya pencegahan, deteksi dini dan pengobatan komplikasi dan penyakit yang mungkin terjadi, serta penyediaan pelayanan pemberian ASI, cara menjarangkan kehamilan, imunisasi, dan nutrisi bagi ibu. Periode pasca persalinan meliputi masa transisi kritis bagi ibu, bayi dan keluarganya secara fisiologis, emosional dan sosial.Baik di negara maju maupun negara berkembang, perhatian utama bagi ibu dan bayi terlalu banyak tertuju pada masa kehamilan dan persalinan.Asuhan masa nifas diperlukan dalam periode ini karena merupakan masa kritis baik ibu maupun bagi bayinya. Diperkirakan 60\% kematian ibu diakibatkan oleh perdarahan yang terjadi setelah persalinan dan $50 \%$ kematian masa nifas terjadi dalam 24 jam pertama (Heryani, 2012).

Beberapa bakteri dapat menyebabkan infeksi setelah persalinan.Infeksi masa nifas masih merupakan penyebab tertinggi AKI.Infeksi alat genetal merupakan komplikasi masa nifas.Infeksi yang meluas ke saluran urinari, payudara, dan pembedahan merupakan penyebab terjadinya AKI (Heryani, 2012).Infeksi nifas ditandai dengan suhu $38^{\circ} \mathrm{C}$ atau lebih yang terjadi antara hari ke $2-10$ hari postpartum dan diukur paling sedikit 4 kali sehari.Kenaikan suhu tubuh yang terjadi di dalam masa nifas yang di anggap sebagai infeksi nifas, jika tidak ditemukan sebab-sebab ekstra genitalia (Listinawati, 2013).

Pelayanan nifas adalah pelayanan kesehatan sesuai dengan standar pada ibu mulai 6 jam sampai 42 hari pasca persalinan oleh tenaga kesehatan. Untuk deteksi dini komplikasi pada ibu nifas diperlukan pemantauan pemeriksaan terhadap ibu 
nifas dengan melakukan kunjungan nifas minimal 3 kali dengan waktu: 1) Kunjungan nifas pertama (KF1) pada 6 jam setelah persalinan sampai 7 hari; 2) Kunjungan nifas kedua (KF2) dilakukan pada minggu ke-2 setelah persalinan; dan 3) kunjungan nifas ketiga (KF3) dilakukan minggu ke-6 setelah persalinan.(Kemenkes RI, 1997). Cakupan pelayanan nifas di Provinsi Sumatra Selatan tahun 2014 mencapai 88,71\%. Cakupan pelayanan nifas di Kabupaten/Kota berkisar antara 68,57\%98,07\%. Capaian KF tertinggi terjadi di Kabupaten OKU Selatan $(98,07 \%)$, kemudian diikuti kota Prabumulih $(95,14 \%)$ dan Kabupaten Lahat $(95,07 \%)$. Sedangkan cakupan terendah terjadi di Kabupaten Musi Banyuasin (68,57\%) dan Kabupaten Empat Lawang (84,62\%) (Dinkes Sumsel, 2014).

Perawatan luka perineum pada masa nifas merupakan suatu perilaku yang seharusnya dilakukan oleh seorang ibu dalam masa nifas dimana perawatan luka perineum akan dapat mencegah terjadinya infeksi pada luka perineum.Secara teoritis perawatan luka perineum dapat dilakukan dengan cara memberi kompres es pada bagian luka perineum; memberikan cairan antiseptik seperti povidone iodine; dan melakukan senam kegel.

Sebagian besar pengetahuan manusia didapatkan dari pendidikan, pengalaman sendiri atau pengalaman orang lain sehingga pengetahuan akan sangat penting dalam membentuk perilaku seseorang. Pengalaman dalam perawatan luka perineum pada ibu nifas dapat dipengaruhi oleh jumlah anak/paritas yang dimiliki seorang ibu.Hasil penelitian yang dilakukan oleh Suryati, dkk (2013) menyatakan bahwa ada hubungan yang signifikan ( $\rho$ value 0,030$)$ antara tingkat pengetahuan ibu nifas tentang perawatan luka perineum dengan proses penyembuhan luka.

Berdasarkan data dari Bidan Praktik Mandiri (BPM) Ratna Wilis Palembang didapatkan ibu yang melakukan kunjungan nifas tahun 2016 yaitu sebanyak 163 orang, pada tahun 2017 ibu yang melakukan kunjungan nifas yaitu sebanyak 179 orang.

Tujuan penelitian ini adalah untuk mengetahui hubungan antarapengetahuan dan paritas ibu dengan perawatan luka perineum di Bidan Praktik Mandiri Ratna Wilis Palembang tahun 2018.

\section{Metode Penelitian}

Penelitian ini menggunakan survey analitik, desain penelitian yang akan dilakukan dalam penelitian ini adalah dengan desain cross sectional. Sampel dalam penelitian ini adalah sebagian ibu postpartum yang dirawat atau yang melakukan kunjungan masa nifas di BPM Ratna Wilis Palembang tahun 2018. Dari hasil pengambilan sampel secara accidental sampling didapatkan sebanyak 32 responden.Penelitian ini dilaksanakan pada bulan November 2018- Januari 2019 diBidan Praktik Mandiri Ratna Wilis Palembang tahun 2018 dimana sebelum melakukan pengambilan sampel peneliti telah mendapatkan izin penelitian dari Lembaga Penelitian Pengabdian Masyarakat STIKES 'Aisyiyah Palembang dengan nomor 125/STIKES/D-4/IX/2018 dan juga telah mendapat persetujuan dari pimpinan Bidan Praktik Mandiri Ratna Wilis Palembang.

Teknik pengumpulan data dengan data primer yaitu dengan wawancara dan observasi pengamatan langsung kepada responden dengan alat bantu kuesioner dan lembar observasi. Instrumen pengumpulan data adalah dalam bentuk kuesioner sesuai dengan variabel independen yang diteliti yaitu pengetahuan dan paritas ibu sedangkan untuk variabel dependen yaitu perawatan luka perineum menggunakan lembar observasi berupa cheklist hasil pengamatan.

Untuk variabel pengetahuan dalam penelitian ini berjumlah 10 pertanyaan pilihan ganda, untuk setiap item pertanyaan dalam kuesioner pengetahuan, jika dijawab dengan benar diberi nilai 10 sedangkan untuk setiap item pertanyaan yang dijawab salah atau kosong (tidak dijawab) akan diberi nilai 0. Dapat dikatakan pengetahuan baik jika total nilainya > 50, sedangkan pengetahuan kurang baik jika total nilainya $\leq$ 50.Untuk variabel paritas dalam penelitian ini di sesuaikan dengan identitas responden yang di tulis pada lembar kuesioner.Dapat dikatakan paritas tinggi bila ibu mempunyai anak $\geq 3$, sedangkan paritas rendah bila ibu mempunyai anak < 3. Untuk variabel perawatan luka perineum dalam penelitian ini ada 5 hal yang di observasi. Dapat dikatakan perawatan luka perineum baik jika dari 5 hal yang di observasi semua hasilnya tidak, sedangkan perawatan luka perineum kurang baik jika dari 5 hal yang di observasi ada hasilnya yang iya.

Analisis data hasil penelitiandilakukan seacaraanalisis univariat dan bivariat dimana 
analisis bivariat menggunakan uji statistik chisquare dengan taraf signifikasi $(\alpha 0,05)$.

\section{Hasil dan Pembahasan}

\section{Analisis Univariat}

Berdasarkan hasil penelitian pada analisa univariat terhadap variabel paritas, umur,

Tabel 1

Distribusi Frekuensi Responden Berdasarkan Umur, Pekerjaan, Pendidikan, Pengetahuan, Paritas, dan Perawatan Luka Perineum di Bidan Praktik Mandiri Ratna Wilis PalembangTahun 2018

\begin{tabular}{|c|c|c|c|}
\hline No & Variabel & Frekuensi (f) & Presentase (\%) \\
\hline \multirow[t]{5}{*}{1.} & Umur & & \\
\hline & $15-19$ & 6 & 18,8 \\
\hline & $20-35$ & 20 & 62,5 \\
\hline & $36-42$ & 6 & 18,8 \\
\hline & Jumlah & 32 & 100 \\
\hline \multirow[t]{6}{*}{2.} & Pekerjaan & & \\
\hline & IRT & 19 & 59,4 \\
\hline & Pedagang & 6 & 18,8 \\
\hline & Karyawan Swasta & 3 & 9,4 \\
\hline & Buruh & 4 & 12,6 \\
\hline & Jumlah & 32 & 100 \\
\hline \multirow[t]{6}{*}{3.} & Pendidikan & & \\
\hline & SD & 1 & 3,1 \\
\hline & SMP & 10 & 31,3 \\
\hline & SMA & 17 & 53,1 \\
\hline & PT & 4 & 12,5 \\
\hline & Jumlah & 32 & 100 \\
\hline \multirow[t]{3}{*}{4.} & Perawatan Luka Perineum & 24 & 75 \\
\hline & $\begin{array}{l}\text { Baik } \\
\text { Kurano baik }\end{array}$ & 8 & 25 \\
\hline & Jumlah & 32 & 100 \\
\hline \multirow[t]{4}{*}{5.} & Pengetahuan & & \\
\hline & - Baik & 26 & 81,3 \\
\hline & - Kurang Baik & 6 & 18,8 \\
\hline & Jumlah & 32 & 100 \\
\hline \multirow[t]{4}{*}{6.} & Paritas & & \\
\hline & - $\quad$ Tinggi & 15 & 46,9 \\
\hline & - Rendah & 17 & 53,1 \\
\hline & Jumlah & 32 & 100 \\
\hline
\end{tabular}

Berdasarkan tabel 1 diatas diperoleh hasil distribusi frekuensi berdasarkan umurdari 32 responden, dapat diketahui frekuensi tertinggi yaitu responden yang memiliki umur 20-35 tahun sebanyak 20 responden (62,5\%). Distribusi frekuensi responden berdasarkan pekerjaandari 32 responden, dapat diketahui frekuensi tertinggi yaitu responden yang bekerja sebagai IRT sebanyak 19 responden $(59,4)$. Distribusi frekuensi responden berdasarkan pendidikandapat diketahui frekuensi tertinggi yaitu responden yang berpendidikan SMA pekerjaan, pendidikan, pengetahuan, paritas dan perawatan luka perineum di Bidan Praktik Mandiri Ratna Wilis Palembang Tahun 2018 dapat dilihat pada tabel berikut : 
diketahui frekuensi tertinggi yaitu responden yang memiliki paritas rendah sebanyak 17 responden $(53,1 \%)$

\section{Analisis Bivariat}

Berdasarkan hasil penelitian pada analisa bivariat terdapat variabel independen (pengetahuan, dan paritas) dan variabel dependen (perawatan luka perineum) di Bidan Praktik Mandiri Ratna Wilis Palembang Tahun 2018 dapat dilihat pada tabel berikut :

Tabel 2

Hubungan antara pengetahuan dan paritas dengan perawatan luka perineumdi Bidan Praktik Mandiri Ratna Wilis Palembang Tahun 2018

\begin{tabular}{lcccc}
\hline \multirow{2}{*}{ Variabel } & \multicolumn{2}{c}{ Perawatan Luka Perineum } & \multirow{2}{*}{ Jumlah } & P value \\
\cline { 2 - 3 } & Ya & Tidak & & \\
\cline { 2 - 3 } 1) Pengetahuan & & & & \\
Baik & $24(92,3 \%)$ & $2(7,7 \%)$ & $26(100 \%)$ & 0,000 \\
Kurang Baik & $0(0 \%)$ & $6(100 \%)$ & $6(100 \%)$ & \\
\hline 2) Paritas & & & & \\
Tinggi & $15(100 \%)$ & $0(0 \%)$ & $15(100 \%)$ & 0,003 \\
Rendah & $9(52,9 \%)$ & $8(47,1 \%)$ & $17(100 \%)$ & \\
\hline
\end{tabular}

\section{Hubungan antara pengetahuan Perawatan Luka Perineum}

Hasil analisis bivariat diketahui bahwa responden dengan pengetahuan baik yang melakukan perawatan luka perineum dengan baik sebesar 24 responden $(92,3 \%)$ dan responden berpengetahuan baik yang melakukan perawatan luka perineum dengan kurang baik sebesar 2 responden $(7,7 \%)$, sedangkan dari 6 responden berpengetahuan kurang baik tidak ada yang melakukan perawatan luka perineum dengan baik (0\%) dan responden berpengetahuan kurang baik yang melakukan perawatan luka perineum dengan kurang baik sebesar 6 responden $(100 \%)$.

Dari hasil uji statistik chi square tidak memenuhi syarat untuk uji chi-square sebagai nilai fisher's exact didapatkan nilai $\rho$ value $(0,000)<\alpha$ $(0,05)$ yang berarti secara statistik bahwa ada hubungan antara pengetahuan ibu dengan perawatan luka perineum di BPM Ratna Wilis Palembang tahun 2018.

Penelitian ini sesuai dengan teori Walyani (2015) dimana pengetahuan tentang luka perineum merupakan pemahaman ibu untuk merawat luka perineum dengan baik agar tidak terjadi infeksi yaitu dengan cara melakukan kompres es pada daerah luka perineum untuk mengurangi rasa nyeri; memberikan cairan antiseptic seperti povidone iodine pada daerah luka perineum; dan melakukan senam kegel. Perawatan luka perineum bisa dilakukan pada saat mandi, saat buang air kecil, dan saat buang air besar.

Dengan pengetahuan yang baik ibu dapat melakukan perawatan luka perineum dengan baik.Pengetahuan merupakan faktor penting dalam perawatan luka perineum, bila seorang ibu yang memiliki luka perineum kurang pengetahuannya tentang perawatan luka perineum maka ibu berisiko mengalami infeksi yang bisa membahayakan dirinya.

Penelitian ini sejalan dengan penelitian Suryati, dkk. (2013), dengan judul hubungan tingkat pengetahuan ibu nifas tentang perawatan luka perineum dan status gizi dengan proses penyembuhan luka di Poli KIA RS. Pantiwilasa Citarum. Hasil univariat menunjukkan bahwa dari 40 responden, sebanyak 28 responden $(70 \%)$ yang memiliki tingkat pengetahuan baik tentang perawatan luka perineum, 31 responden $(77,5 \%)$ yang memiliki status gizi baik, 25 responden $(62,5 \%)$ yang melalui proses penyembuhan luka normal. Dari hasil uji statistik chi square diketahui bahwa ada hubungan antara pengetahuan $(\rho$ value $=0,03)$, status gizi $(\rho$ value $=0,008)$ dengan proses penyembuhan luka. Hasil penelitian yang dilakukan Kurniati, dkk.(2014), dengan judul analisis pengetahuan dan tindakan senam kegel terhadap penyembuhan luka perineum pada ibu nifas di wilayah kerja puskesmas purwokerto selatan. Hasil univariat menunjukakan bahwa dari 34 responden, sebanyak 14 responden $(31,8 \%)$ yang memiliki tingkat pengetahuan baik tentang 
penyembuhan luka perineum, 13 responden (29,5\%) yang memiliki pengetahuan cukup baik tentang penyembuhan luka perineum, 17 responden $(38,6 \%)$ yang memiliki pengetahuan kurang baik tentang penyembuhan luka perineum. Berdasarkan uji chi-square $p$ value $=0,003$ dengan demikian terdapat hubungan yang signifikan antara pengetahuan senam kegel terhadap penyembuhan luka perineum pada ibu nifas.

Berdasarkan uraian tersebut dapat disimpulkan bahwa responden yang berpengetahuan baik cenderung akan melakukan perawatan luka perineum dengan baik dibandingkan dengan responden yang berpengetahuan kurang baik. Hal ini dikarenakan ibu yang tingkat pengetahuannya baik lebih memahami cara dan manfaat perawatan luka perineum, sedangkan ibu yang tingkat pengetahuannya kurang baik cenderung kurang memahami cara dan manfaat perawatan luka perineum.

\section{Hubungan antara Paritas dengan Perawatan Luka Perineum}

Hasil analisis bivariat diketahui bahwa responden dengan paritas tinggi yang melakukan perawatan luka perineum dengan baik sebesar 15 responden $(100 \%)$ dan responden dengan paritas tinggi tidak ada yang melakukan perawatan luka perineum dengan kurang baik (0\%), sedangkan dari 17 responden paritas rendah yang melakukan perawatan luka perineum dengan baik sebesar 9 responden $(52,9 \%)$ dan responden dengan paritas rendah yang melakukan perawatan luka perineum dengan kurang baik sebesar 8 responden $(47,1 \%)$.

Hasil uji statistik chi square tidak memenuhi syarat untuk uji chi-square sebagai nilai fisher's exact didapatkan nilai $\rho$ value $(0,003)<\alpha(0,05)$ yang berarti secara statistik bahwa ada hubungan antara paritas ibu dengan perawatan luka perineum di BPM Ratna Wilis Palembang tahun 2017.

Penelitian ini sesuai dengan teori Walyani (2015), paritas adalah keadaan wanita berkaitan dengan jumlah anak yang dilahirkan. Paritas anak kedua dan ketiga merupakan paritas paling aman ditinjau dari sudut kematian maternal.Pada paritas tinggi $\geq 3$ mempunyai angka kematian maternal lebih tinggi.Ibu-ibu yang mempunyai anak < 3 (paritas rendah) dapat di kategorikan pemeriksa kehamilan dengan kategori baik.

Penelitian ini sejalan dengan penelitian Chasanah, dkk (2015), dengan judul gambaran perilaku dalam perawatan luka perineum di Kelurahan Kabupaten Brebes. Hasil univariat menunjukkan bahwa dari 40 responden, sebanyak 26 responden $(65 \%)$ yang memiliki umur 20-35 tahun, 21 responden $(52,5 \%)$ yang memiliki pendidikan SD/SMP, 24 responden $(60 \%)$ yang memiliki paritas multipara. Dan penelitian Tulas (2016) dengan judul hubungan perawatan luka perineum dengan perilaku personal higiene ibu post partum di Rumah sakit Pancaran Kasih GMIM Manado. Hasil univariat menunjukan dari 56 responden, sebanyak 27 responden $(48,2 \%)$ memiliki paritas 1,21 responden $(37,5 \%)$ yang memiliki paritas 2, 6 responden $(10 \%)$ yang memilik paritas 3, 2 responden $(3,6 \%)$ yang memiliki paritas 4. Berdasarkan hasil uji chisquare dengan komputerisasi didapatkan bahwa $p$ value $=0,001$ dimana lebih kecil dari nilai $\alpha$ yang ditetapkan $(\alpha=0,005)$. Maka Ha diterima hal ini berarti ada hubungan antara perawatan luka perineum dengan perilaku personal hygiene pada pasien ibu post partum.

Uraian tersebut dapat disimpulkan bahwa responden dengan paritas tinggi cenderung akan melakukan perawatan luka perineum dengan baik dibandingkan responden dengan paritas rendah. Hal ini dikarenakan ibu dengan paritas tinggi sudah memiliki pengalaman terdahulu tentang perawatan luka perineum sehingga ibu melakukan perawatan dengan baik, sedangkan ibu dengan paritas rendah belum memiliki pengalaman tentang perawatan luka perineum sehingga ibu kurang mengerti cara melakukan perawatan luka perineum yang baik.

\section{Simpulan}

Dari hasil penelitian yang telah diuraikan sebelumnya, maka dapat ditarik kesimpulan yaitu:Sebagian besar responden melakukan perawatan luka perineum dengan baik yaitu sebanyak 24 responden (75\%).Sebagian besar responden berpengetahuan baik yaitu sebanyak 26 responden (81,3\%).Sebagian besar responden dengan paritas tinggi yaitu sebanyak 15 responden (46,9\%).Ada hubungan secara statistik antara pengetahuan dengan perawatan luka perineum dengan $\rho$ value $(0,000)<\alpha(0,05)$. Ada hubungan secara statistik antara paritas dengan perawatan luka perineum dengan $\rho$ value $(0,003)<\alpha(0,05)$.

Melihat hasil penelitian diatas, ada beberapa saran yang perlu disampaikan dan ditindak lanjuti, yaitu: Bagi institusi kesehatan diharapkan dapat melakukan penyuluhan tentang perawatan luka 
perineum maupun konseling secara langsung kepada masyarakat agar pengetahuan warga setempat dapat bertambah. Hal ini di tujukan agar masyarakat mempunyai pandangan yang benar tentang perawatan luka perineum. Bagi institusi pendidikan diharapkan dapat meningkatkan penyediaan buku-buku sumber untuk bacaan guna menambah ilmu dan pengetahuan serta dapat digunakan untuk melengkapi referensi kepustakaan yang menunjang penelitian selanjutnya.Dari hasil penelitian ini diharapkan bagi peneliti yang akan datang dapat mengembangkan penelitian tersebut dengan variabel-variabel lain yang berhubungan tentang perawatan luka perineum sehingga dapat menambah pengetahuan bagi para ibu untuk melakukan perawatan perineum dengan baik.

\section{Daftar Pustaka}

Budiman; Riyanto, A. (2013).Kapita Selekta Kuesioner Pengetahuan dan Sikap dalam Penelitian Kesehatan. Jakarta: Salemba Medika.

Chasanah Siti Nur; Sutanto, Dedi; Arisanti, N. L. (2015).Gambaran Perilaku Ibu Nifas Dalam Perawatan Luka Perineum Di Kelurahan Kabupaten Brebes.Jurnal Siklus, IV(1), 6567.

https://doi.org/http://dx.doi.org/10.30591/sik lus.v4i1.244.g239

Dinas Kesehatan Provinsi Sumatera Selatan. (2014). Profil Kesehatan Provinsi Sumatera Selatan Tahun 2014. Sumatera Selatan.

Heryani, R. (2002). Asuhan Kebidanan Ibu Nifas Dan Menyusui. Jakarta: CV Trans Info Media.

Hidayat, A. A. (2007). Metode Penelitian Kebidanan Teknik Analisis Data. Jakarta: Salemba Medika.
Kementerian Kesehatan RI. (1997). Kementerian Kesehatan RI Buku Kesehatan Ibu dan Anak. Jakarta: Kementerian Kesehatan dan JICA.

Kurniati, Citra Hadi; Wulan, Intan Sari; Hikmawati, I. (2014).Analisis Pengetahuan Dan Tindakan Senam Kegel Terhadap Penyembuhan Luka Perineum Pada Ibu Nifas Di Wilayah Kerja Puskesmas Purwokerto Selatan.Jurnal Pharmacy, 11(1), 26-39.

https://doi.org/http://dx.doi.org/10.30595/pji. v11i1.846

Listinawati, L. (2013). Asuhan Kebidanan Terkini Kegawatdaruratan Maternal Neonatal. Jakarta: CV Trans Info Media.

Maryunani, A. (2011). Asuhan Pada Ibu Dalam Masa Nifas (Postpartum). Jakarta: CV Trans Info Media.

Notoatmodjo, S. (2012).Metodologi Penelitian Kesehatan. Jakarta: Rineka Cipta.

Notoatmodjo, S. (2011).Kesehatan Masyarakat Ilmu Dan Seni. Jakarta: Rineka Cipta.

Suryabrata, S. (2014).Metodologi Penelitian. Jakarta: Rajawali Press.

Suryati, Yayat; Kustati, Eni; Hastuti, W. (2013).Hubungan Tingkat Pengetahuan Ibu Nifas Tentang Perawatan Luka Perineum Dan Status Gizi Dengan Proses Penyembuhan Luka.Jurnal Manajemen Keperawatan, 1(1), 25-32.

Tulas, Verby Divini Prety; Kundre, Rina; Bataha, Y. (2017).Hubungan Perawatan Luka Perineum Dengan Perilaku Personal Hygiene Ibu Post Partum Di Rumah Sakit Pancaran Kasih GMIM Manado.e-journal keperawatan, 5(1), 1-9

Walyani, E. S. (2015). Asuhan Kebidanan Kegawatdaruratan Maternal Dan Neonatal. Yogyakarta: Pustaka Baru Press. 